\title{
The Influence of Educational Beliefs in a Developmentally Appropriate Practice to Mathematics Pedagogical Content Knowledge of Early Childhood Teachers: Focusing on the Mediating Effects of Curriculum Implementation
}

Sunyoung Yang, Jihyun Kim

Dept. of Child Development \& Education, Myongji University, Seoul, Korea

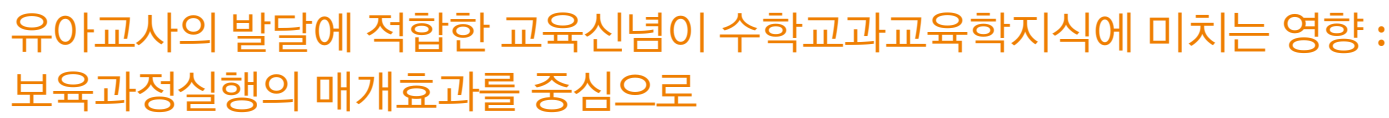

양선영, 김지현

명지대학교 아동학과

Objective: The purpose of this study is to examine the direct and indirect effects of early childhood teachers' educational beliefs in a developmentally appropriate practice (DAP) on mathematics pedagogical content knowledge (MPCK) via curriculum implementation. It also examines whether this pathway differs according to the experience of the teacher education on the early childhood mathematics during their pre-service or in-service period.

Methods: For this purpose, 327 early childhood teachers of childcare centers in Seoul and the metropolitan area answered a questionnaire. Stepwise multiple regression analysis was used to analyze the data.

Conclusion: The teachers' educational beliefs in DAP predicted MPCK directly as well as indirectly through curriculum implementation. In addition, when teachers had experienced pre-service or inservice teacher education on the early childhood mathematics, the teachers' educational beliefs in DAP had a direct influence on the MPCK and an indirect one through the curriculum implementation. However, when teachers had not experienced that type of training, beliefs in DAP were indirectly influenced by curriculum implementation. The results of this study can be used to explore ways to improve teachers' mathematics pedagogical content knowledge and contribute to the development of teachers' education programs.

Keywords: mathematics pedagogical content knowledge, educational beliefs in DAP, curriculum implementation, experience of teacher education on the early childhood mathematics, early childhood teacher

\footnotetext{
서론

인간은 수학적 능력을 가지고 태어난다. 아주 어린 영아들도

Corresponding Author: Jihyun Kim, Dept. of Child Development \& Education, Myongji University, 34, Geobukgol-ro, Seodaemun-gu, Seoul, Republic of Korea

E-mail: jihunkim@mju.ac.kr
}

적은 양일 경우 수량화하는 능력을 보일뿐만 아니라(Geary, 1994 ) 유아들도 성인의 도움 없이 일상생활이나 놀이를 하면 서 수학적 관계를 탐색하고 수학적인 개념들을 경험하며 능동

(C)The Korean Association of Child Studies

This is an Open Access article distributed under the terms of the Creative Commons Attribution Non-Commercial License (http:// creativecommons.org/licenses/by-nc/4.0) which permits unrestricted noncommercial use, distribution, and reproduction in any medium, provided the original work is properly cited. 
적인 문제해결 속에서 비형식적인 수학지식을 형성하는 능력 이 있다(K. S. Lee, 2008). 영유아는 타고난 수학적 능력을 바탕 으로 일상생활 중에 유의미한 타인과의 상호작용을 통해 수학 적 능력을 지속적으로 발달시켜 나가기 때문에 영유아 보육. 교육현장에서 질적으로 우수한 영유아수학활동이 필요하다 (H. Hong, 2010).

유아는 일상생활에서 직관적이고 비형식적 지식으로 얻은 경험이나 지식을 형식적 지식으로 전환하는 과정을 통해 수 학적 체계를 구성해 간다. 유아에게 질 높은 유아수학교육을 제공하기 위해서는 유아에게 의미가 있으면서도 유아의 사전 지식이나 흥미가 수학학습과 연결되어야 하며(Cross, Woods, \& Schweingruber, 2009) 교수전략을 통해 유아의 다양한 경험 이나 상황을 수학적 이해로 안내하는 놀이와 같으면서도 잘 조직화된 수학교육과정이 필요하다(Ginsburg, 2006). Aubrey (1994)는 수학교과교육학지식이 높은 교사는 유아가 자신의 다양한 경험을 수학적으로 의미 있게 확장하도록 계획하고, 다양한 수학적 방법으로 표현하도록 하며, 보다 역동적으로 가르치고, 유아들의 질문에 풍부하게 반응한다고 하였다. 그 러나 유아교사들은 일반적으로 유아의 수학적 사고와 지식획 득에 대해 낮은 기대를 가지고 있고, 유아들에게 인지적 사고 를 요구하는 활동을 해서는 안 된다는 교육신념을 가지고 있 다(Ginsburg \& Ertle, 2008). 또한 유아교사들은 수학교수에 대 한 기초지식이 미흡하고, 내용체계에 대한 이해 역시 부족하 다(H. Hong, 2010). 이는 유아의 수학활동을 촉진시키고 유아 의 학습과 발달에 영향력이 가장 큰 요인이 교사임(Kye, 2011) 을 고려할 때, 유아교사의 유아수학활동에 대한 전문적 자질 확보가 필요하다.

최근 국내에서는 유아수학교육의 교과내용 및 교수학습방 법에 대한 지식을 갖추고 유아의 수학적 능력 발달수준과 보 육과정을 고려하여 유아에게 수학활동을 제공하는 교수능력 인 유아교사의 수학교과교육학지식(Mathematics Pedagogical Content Knowledge [MPCK])이 강조되고 있다(H. Hong, 2014). 교과교육학지식이 능력 있는 교사의 중요한 준거로 거 론되면서(Van Driel, Beijaard, \& Verloop, 2001) 교사들이 어떻 게 교과교육학지식을 형성하는지, 혹은 보육과정의 어떤 요소 가 이 지식의 계발에 도움이 되는지에 대한 연구의 필요성이 강조되고 있다(Shulman, 1986). 그러나 수학교과교육학지식 관련 국내연구는 주로 유아교사의 교수적 내용지식에 대한 구 성요소(B. W. Cho, 2010), 수학교과교육학지식의 필요성 인식 (H. Hong, 2014), 수학교수효능감과의 관계(S. R. Kim, 2017; J. E. Kim, 2014; Seo, 2017), PCK에 기반한 유아수학교육 교사
프로그램의 효과(J.-E. Kim \& Hong, 2015), 유아교사의 수학 교과교육학지식 관련 변인(S. Yang \& Kim, 2017; H. J. Hong, 2013) 등이 이루어진 수준이다.

교사의 교과교육학지식에 대한 논의에서 자주 인용되어지 는 연구자인 Shulman (1986)의 교과교육학지식은 초중등 교사 에게 요구되는 것으로(Bredekamp \& Rosegrant, 1992), 유아교 사에게 요구되는 지식기반으로 그대로 차용하는 것은 적절하 지 못하다(J.-W. Lee, 2000). 이에 본 연구에서는 유아수학교육 의 교과교육학지식은 교과내용에 대한 지식에 기초하여 유아 가 수학적 과정을 효과적으로 경험하도록 유아의 발달적 특성 과 교수학습 상황에 맞는 교수방법을 적용하는 것(N.-H. Kim, Seo, \& Shon, 2017)으로 정의한다. 즉, 교사는 유아의 수학적 능력 발달을 일차적 학습목표로 하되 유아의 일상생활이나 놀 이 상황에서 일어나는 수학상황을 학습과 연계하는 의도적 교 수 활동을 제공하고(H. Hong, 2010), 다양한 교구를 활용한 구 체적 조작경험과 교사 및 또래와의 상호작용이 자연스럽게 이 루어질 수 있도록 적절한 환경을 구성하며(H.-J. Lee, Ham, \& $\mathrm{Kim}, 2003)$, 교사가 교수적 상호작용에 능동적으로 참여하여 안내하는 교수접근(Golbeck, 2001)을 적용하는 것이 유아수학 교육에 필요한 교과교육학지식의 기반이다.

미국유아교육협회(NAEYC)에 의해 발달에 적합한 실제 (Developmentally Appropriate Practice [DAP])가 제시된 이후, 이는 유아보육의 핵심 개념이 되어오고 있다(J.-W. Lee, 2000). $\mathrm{DAP}$ 란 유아보육에 있어 연령 적합성과 개별적 발달 적합성 이라는 2 가지 개념에 따라 다양한 환경을 제공하고 교육하 는 것으로(J. S. Lee \& Oh, 2006) 유아를 지식 구성자로 보는 Piaget와 Vygotsky의 이론을 반영한 것이다(Hwang \& Kang, 2003). 이러한 관점을 지닌 교사는 학습자에게 일상생활 중에 의미 있는 수학활동을 제공하여 스스로 문제를 해결하도록 하 며, 이 과정에서 수학적 과정과 문제해결의 수학적 전략을 강 조하고, 상호 수학적으로 토의하는 것을 주요시하는 교수-학 습방법을 선호한다(Han, 2010). 이는 유아교사의 수학교과교 육학지식이 자유선택활동이나 일상생활 속에서 수학적 개념 을 발견하고 발달에 적합한 교수법을 통해 유아가 그 개념을 학습할 수 있도록 이끈다는 것(N. Y. Kim \& Park, 2017)과 일맥 상통한다. 따라서, 유아교사를 위한 수학교과교육학지식에 유 아의 연령별, 개별 발달의 적합성에 근거를 두고 있는 발달에 적합한 교육신념이 반영되어 있음을 알 수 있다.

이에 이 연구에서는 유아교사의 수학교과교육학지식에 영 향을 주는 첫 번째 변인으로 유아교사의 발달에 적합한 교육 신념을 살펴보고자 한다. 교사의 교육신념은 교사가 수행하 
는 모든 교육적 행동양식의 정신적 기본이 된다(Thompson, 1992). 또한 교과교육학지식은 교사의 사적인 지식으로 개인 의 교육경험에 바탕하며, 서로 다른 교사지식과 교육적 신념 간의 상호작용의 결과이다(Hashweh, 2005). 즉 교사의 교육신 념을 바탕으로 교과교육학지식은 교수계획으로 나타나며 교 수경험과 반성의 과정을 통해 교사의 교실 안에서의 행동과 관련되어 진다(Gess-Newsome \& Lederman, 1999). 국내 선행 연구에서도 교사의 교육신념이 교사의 수업전문성과 수업활 동에 직접적인 영향을 줄 수 있다고 하였으며(I. J. Cho, 2008), 예비교사들의 수학에 대한 신념과 수학교수에 대한 신념, 수 학학습에 대한 신념 등은 서로 다른 수학교과교육학지식 구성 요소에 영향을 주는 관계라고 하였다(Choi-Koh, Kim, Moon, $\mathrm{Bae}, \&$ Jeong, 2011). 특히, 현재 발달에 적합한 교육신념은 우 리나라에서도 영유아보육현장에서의 표준보육과정, 누리과 정, 평가인증 지침서에 반영되어 직무교육, 승급교육 및 교사 교육 등의 여러 경로를 통해 교사들에게 교육되어지고 있다(J. M. Lee, 2007). 그러므로 발달에 적합한 교육신념이 수학교과 교육학지식과 관련성이 있음을 예측할 수 있다.

유아교사의 수학교과교육학지식에 영향을 주는 두 번째 변 인으로 보육과정실행을 살펴보고자 한다. 보육과정실행은 개 발된 보육과정의 교육목표와 내용, 교육계획, 교수학습방법, 평가를 보육현장에서 교사가 실천해 나가는 활동을 의미한다 (Park, 2009). 교과교육학지식은 교사의 반성적 수업 실천을 통해 향상되며, 이론 중심의 강의를 통해서 획득되기 어렵고 (Choe \& Hwang, 2009), 교사의 경험에 따라 계속적으로 재구 성 과정을 거치면서 더욱 효율적이고 전문적인 교사의 지식이 되는 경험적 - 실천적 지식이다(Lim, 2003). 교과교육학지식이 고정되어 있지 않고 교수 경험을 통해 지속적으로 재구성되어 가는 지식이라는 점은 유아교사가 보육과정실행을 통해 수학 교과교육학지식이 향상될 가능성을 시사한다. 실제로 유아교 사의 보육과정실행 정도가 높을수록 수학교과교육학지식도 높았다(S. Yang \& Kim, 2017). 그러므로 일상생활과 놀이에서 타교과와의 통합 운영을 지향하는 국가수준의 보육과정인 누 리과정실행이 수학교과교육학지식에 영향을 미칠 것으로 예 측된다.

그런데, 발달에 적합한 교육신념은 보육과정실행을 예측하 기도 한다(Y. H. Kwon, Choi, \& Rha, 2011). 유아교사가 개인적 으로 형성한 교육신념은 보육과정을 계획하고 실행할 때, 학급 에서의 크고 작은 의사결정을 할 때 영향을 미치게 된다(C. G. Kwon, 1998). 또한 비슷한 수학지식을 지닌 교사라 하더라도 자신의 교육신념에 따라 같은 내용을 다르게 해석하여 가르칠
수 있기 때문에(Emest, 1989), 보육과정실행에 변화를 가져오 고자 할 때에는 교사의 교육신념이 어떠한가에 따라 변화의 성 공과 실패가 좌우되기도 한다(Spillane, 2000). 우리나라 국가수 준의 보육과정인 누리과정에는 발달에 적합한 교육신념이 반 영되어(Ministry of Health \& Welfare [MHW], 2014) 보육현장 의 교사들의 교육신념체계에 영향을 주고 있다. 유아교사가 발 달에 적합한 교육신념이 높을수록 발달에 적합한 유아보육 실 제를 더 많이 실행하며(S. A. Lee \& Lee, 2007), 특히, 유아보육 분야와 아동발달 분야의 재교육을 받은 교사가 발달에 적합한 교육신념과 발달에 적합한 교수활동 실행이 높았고, 높은 질의 유아보육 프로그램을 운영하는 교사는 낮은 질의 프로그램을 운영하는 교사보다 발달에 적합한 교육신념과 발달에 적합한 교수활동이 높게 나타났다(Nam \& Hwng, 2001). 이상을 살펴 봤을 때 유아교사의 발달에 적합한 교육신념은 보육과정실행 에 영향을 미치고 있을 것으로 가정할 수 있다. 이와 같이 발달 에 적합한 교육신념이 보육과정실행을 예측하는 것은 보육과 정실행이 발달에 적합한 교육신념과 유아교사의 수학교과교 육학지식 사이를 매개하는 변인으로 역할할 가능성을 시사한 다. 즉, 유아교사의 발달에 적합한 교육신념은 수학교과교육 학지식을 직접적으로 예측함과 동시에 보육과정실행을 통해 서도 간접적으로 수학교과교육학지식을 예측하는 중요한 변 인일 가능성이 있다. 이에 이 연구에서는 이 변인들 간의 매개 모형이 실제로 유효한지 검증하는데 목표를 둔다.

한편, 유아교사가 양성 및 현직 과정에서 유아수학 관련 교 사교육경험에 따라 보육과정실행이 발달에 적합한 교육신념 과 수학교과교육학지식 간의 관계를 매개하는 정도에 차이가 발생할 것으로 예상된다. 수학교과교육학지식이 유아의 수학 적 능력 발달수준과 보육과정을 고려하여 유아에게 수학활동 을 제공하는 교수능력(H. Hong, 2014)이라는 점은 발달에 적 합한 교육신념이 수학교과교육학지식의 기반을 이루는 교육 신념이 될 수 있음을 의미한다. 유아교사가 양성 및 현직 과정 에서 유아수학 관련 교사교육경험에 따라 발달에 적합한 교 육신념이 수학교과교육학지식에 미치는 영향의 직간접성 여 부가 달라질 수 있음을 시사한다. 왜냐하면 수학교과교육학 지식은 교사의 경험에 따라 계속적으로 재구성 과정을 거치 면서 교사의 지식이 되는 경험적이고 실천적 지식이기에(Lim, 2003), 유아수학 관련 교사교육경험이 없는 유아교사의 경우 에는 보육과정을 실행하는 실천적 과정을 통해서만 발달에 적 합한 교육신념이 수학교과교육학지식과 관련이 있음을 인식 할 가능성이 있기 때문이다. 그러므로 유아교사가 양성 및 현 직 과정에서 유아수학에 대한 교사교육경험에 따라 보육과정 
Table 1

General Characteristics of Early Childhood Teachers

\begin{tabular}{llr}
\hline & Variables & Frequency (\%) \\
\hline Age & 20 's & $118(36.1)$ \\
& 30 's & $144(44.0)$ \\
& 40 or more & $65(19.9)$ \\
Teaching experience & Less than 3 years & $68(20.8)$ \\
& 3 years $\sim 5$ years & $96(29.4)$ \\
& 5 years $\sim 10$ years & $120(36.7)$ \\
Education & 10 years or more & $43(13.1)$ \\
& Less than college graduate(2 or 3 years) & $163(49.8)$ \\
Institution type & University graduate(4 years) or more & $164(50.2)$ \\
& National Public childcare center & $109(33.3)$ \\
& Private childcare center & $108(33.0)$ \\
Pre-service teacher education on the early & Workplace childcare center & $110(33.6)$ \\
childhood mathematics & Experience & $229(70.0)$ \\
In-service teacher education on the early & No experience & $98(30.0)$ \\
childhood mathematics & Experience & $154(47.1)$ \\
\hline
\end{tabular}

Note. $N=327$.

실행이 발달에 적합한 교육신념과 수학교과교육학지식 간의 관계를 매개하는 정도에 차이가 있는지를 알아볼 필요가 있다.

따라서 이 연구는 유아교사의 발달에 적합한 교육신념이 보육과정실행을 통해 수학교과교육학지식에 직 - 간접적으로 영향을 미치는 경로를 검증하고, 이 경로가 유아교사의 양성 및 현직 과정에서의 유아수학 관련 교사교육경험에 따라 다른 양상을 보이는지를 검증하고자 한다. 이 연구는 유아교사의 수학교과교육학지식 형성에 도움을 줄 수 있는 교사교육 프로 그램 개발을 위한 기초자료를 제공할 것으로 기대되며, 궁극 적으로 유아기관에서 발달에 적합한 유아수학활동의 활성화 를 통해 보육현장의 유아수학프로그램의 질적 제고에 기여할 것이다. 이를 위한 구체적 연구문제는 다음과 같다.

\section{연구문제 1}

유아교사의 보육과정실행은 발달에 적합한 교육신념이 수학 교과교육학지식에 미치는 영향을 매개하는가?

\section{연구문제 2}

유아교사의 발달에 적합한 교육신념이 수학교과교육학지식에 미치는 영향을 보육과정실행이 매개하는 정도는 유아수학에 대한 교사교육경험(양성과정이수, 현직과정연수)에 따라 상이 한가?

\section{연구방법}

\section{연구대상}

본 연구는 서울 및 수도권의 어린이집(국공립, 민간, 직장)에 재직 중인 유아반 교사 327 명을 대상으로 임의표집하였으며 Table 1은 연구대상의 인구통계학적 배경이다.

\section{연구도구}

\section{수학교과교육학지식}

H. J. Hong (2012)이 개발한 척도를 사용하여 유아교사의 수학 교과교육학지식을 측정하였다. 수학교과교육학지식의 하위 척도는 교육과정(8문항), 교과내용(8문항), 교수학습방법(19 문항), 학습자에 대한 지식(7문항), 전문성 개발(4문항)에 대한 각각의 지식을 측정하는 문항으로 구성되었다. 교육과정에 대 한 지식 하위척도 문항 예시를 든다면 "나는 유아 개개인의 수 학적 경험의 차이를 이해한다.”이다. 각 문항은 교사가 응답하 도록 되어있으며, 5점 Likert척도(매우 그렇다[5점] 절대 그 렇지 않다[1점])로 평정되며, 총점범위는 46점에서 230점이 고, 수학교과교육학지식의 수준이 높을수록 점수가 높다고 해 
석한다. 전체 척도의 신뢰도(Cronbach's $\alpha$ )는 .95로 나타났으 며 하위척도의 신뢰도(Cronbach's $\alpha$ )는 교육과정 .85, 교과내 용 .92, 교수학습방법 .91, 학습자 .89, 전문성개발 .83으로 신 뢰롭게 나타났다.

\section{발달에 적합한 교육신념}

Hart 등(1990)이 개발한 교사신념 질문지(Teacher Belief Scale) 를 S. M. Lee (2003)가 수정, 보완한 도구를 사용하였다. 이 척 도는 총 37문항으로, 발달에 적합한 교육신념(DAP)과 발달에 부적합한 교육신념(DIP) 22 문항과 14 문항으로 구성되었다. 발 달에 적합한 교육신념 문항은 발달에 적합한 실제에 대해 긍정 적으로 진술된 문항으로 구성되어 있으나 발달에 부적합한 교 육신념은 발달에 적합한 실제에 대해 부정적 진술문으로 구성 되어 있어 이 둘을 역산하여 합산해 총점을 산출했다. 발달에 적합한 교육신념 척도문항 예시를 든다면 “유아가 또래 유아 들과의 상호작용을 통해서 배우는 것”이며, 발달에 부적합한 교육신념 척도문항은 "유아에 대한 평가기법으로 표준화된 집 단검사방식”이다. 각 문항은 교사가 응답하도록 되어있으며, 5 점 Likert척도(매우 중요하다[5점] 전혀 중요하지 않다[1점]) 로 평정되며, 총점범위는 36점에서 180점이고, 발달에 적합한 교사의 교육신념이 높을수록 점수가 높게 나타나는 것으로 해 석한다. 전체 척도 신뢰도(Cronbach's $\alpha$ )는 .89로 나타났으며 하 위척도의 신뢰도(Cronbach's $\alpha$ )는 발달에 적합한 교육신념 .92, 발달에 부적한 교육신념 .89로 신뢰롭게 나타났다.

\section{보육과정실행}

Moore 등(1984)이 개발한 교육과정실행(curriculum implementation) 질문지(교사의 교육과정실행 수준(교육철학, 교육목적 및 목 표, 교육내용, 교수학습방법, 교육자료, 아동평가]척도)를 수 정, 보완한 Pu (1998)의 질문지를 재수정한 Sohn (2013)의 도구 를 사용하였다. 본 연구에서는 Shon (2013)의 척도의 의미를 유 지하며 교육과정의 명칭 및 내용을 3-5세 누리과정 유아교사 용 질문으로 수정( 5 세 누리과정」 대신「3 5세 누리과정」으로 수정)하여 사용하였다. 하위척도는 이론적 근거 및 성격(4문 항), 교육목표(6문항), 교육내용(5문항), 교육방법(12문항), 교 육자료(5문항), 교육평가(6문항)로 총 38문항으로 구성되었다. 이론적 근거 및 성격에 대한 하위척도 문항 예시를 든다면 "나 는 「3 5세 누리과정」의 5개 영역을 통합하여 실행한다.”이다. 각 문항은 교사가 응답하도록 되어있으며, 5점 Likert척도(매우
그렇다[5점] 절대 그렇지 않다[1점])로 평정되며, 총점 범위는 38점에서 190점이고, 보육과정실행 수준이 높을수록 점수가 높은 것으로 해석한다. 전체 척도의 신뢰도(Cronbach's $\alpha$ )는 .97 로 나타났으며 하위척도의 신뢰도(Cronbach's $\alpha$ )는 이론적 근 거 및 성격 .86 , 교육목표.86, 교육내용 .84 , 교육방법 .92, 교육 자료 .83 , 교육평가 .88 로 신뢰롭게 나타났다.

\section{연구절차}

아동학 전공 교수, 어린이집 원장 및 아동학 박사과정 재학생, 유아교사 경력자 4 인으로부터 본 조사에 앞서 측정도구의 내 용타당도를 검증하였다. 어린이집 현직 교사 5 인을 대상으로 예비조사를 실시하여 질문지 초안의 안면타당도를 검증하였 다. 이 예비조사를 통해 문항의 내용이 모호한 문항과 실정에 맞지 않는 문항을 일부 수정, 보완하였다.

본 조사는 서울 및 수도권의 어린이집(국공립, 직장, 민간) 현직 유아교사를 대상으로 사전에 전화 및 이메일로 동의를 얻어 방문이나 우편을 통하여 2017년 1월 23일부터 6주간에 걸쳐 어린이집의 교사 수만큼 질문지를 배부하였다. 총 349 부 의 설문지가 회수되었으며 이 중 불성실하게 응답한 교사의 질문지 22 부를 제외한 327 부의 질문지를 연구의 최종 분석자 료로 사용하였다.

\section{자료분석}

이 연구의 연구문제 해결을 위해 SPSS 21.0 (IBM Co., Armonk, $\mathrm{NY}$ ) 프로그램을 이용하여 관찰변수의 정규성을 검증하기 위 해 평균과 표준편차를 산출하였으며, 측정 변수들 간의 관련 성을 알아보기 위해 Pearson의 적률상관계수를 산출하였다. 매 개효과를 알아보기 위해 Baron과 Kenny (1986)의 매개효과 검 증절차에 따라 회귀분석 실시하였다. 회귀분석의 통계적 검증 을 위하여 Sobel test를 실시하였다.

\section{연구결과}

\section{유아교사의 발달에 적합한 교육신념이 보육과 정실행을 통해 수학교과교육학지식에 미치는 직·간접적 영향}

발달에 적합한 교육신념과 수학교과교육학지식 그리고 보육 
Table 2

Descriptive Statistics of Major Variables

\begin{tabular}{lccccc}
\hline \multicolumn{1}{c}{ Variables } & $M$ & $S D$ & Min. & Max. & Range \\
\hline Education belief in DAP & 3.85 & .36 & 3.00 & 4.94 & $1-5$ \\
MPCK & 4.03 & .37 & 2.83 & 5.00 & $1-5$ \\
Curriculum implementation & 4.13 & .45 & 2.89 & 5.00 & $1-5$ \\
\hline
\end{tabular}

Note. $N=327$.

Table 3

Relationship Between Influence of Education Beliefs in DAP, MPCK, Curriculum Implementation

\begin{tabular}{lll}
\hline \multicolumn{1}{c}{ Sub-Variables } & 1 & 2 \\
\hline 1. Education belief in DAP & - & 3 \\
2. MPCK & $.40^{* *}$ & - \\
3. Curriculum implementation & $.41^{* *}$ & $.66^{* *}$
\end{tabular}

Note. $N=327$.

${ }^{* *} p<.01$

과정실행 간의 관계를 살펴보기에 앞서 각 변인들의 평균과 표준편차 산출결과는 Table 2 와 같다. 발달에 적합한 교육신 념은 평균이 3.85점 $(S D=.36)$ 이었고, 수학교과교육학지식은 평균이 4.03점 $(S D=.37)$, 보육과정실행은 평균이 4.13점 $(S D=$ .45)이었다. 이는 연구대상인 유아교사의 발달에 적합한 교육 신념, 수학교과교육학지식, 보육과정실행 수준이 모두 중간 수준보다 높음을 의미한다.

발달에 적합한 교육신념과 수학교과교육학지지식, 보육과 정실행 간의 상관관계를 살펴보기 위해 상관관계분석을 실시 하였다. 상관관계 결과는 Table 3과 같다. 제시된 바와 같이 발 달에 적합한 교육신념과 수학교과교육학지식, 보육과정실행 간의 관계는 유의한 상관관계가 있는 것으로 나타났다. 발달 에 적합한 교육신념은 수학교과교육학지식 $(r=.40, p<.01)$ 과 보육과정실행 $(r=.41, p<.01)$ 과 유의한 정적 상관관계가 있으 며, 수학교과교육학지식은 보육과정실행 $(r=.66, p<.01)$ 과 유 의한 정적 상관관계가 있음을 볼 수 있다.

중다회귀분석에 앞서 독립변인들 간의 다중공선성의 가능 성을 확인하기 위해 상관관계 및 더빈 왓슨 $(\mathrm{D}-\mathrm{W})$ 값, 분산팽 창계수(VIF)를 살펴보았다. 그 결과 상관관계는 .40에서 .80을 넘지 않으며(S. W. Kim \& Choi, 2001), 더빈 왓슨값은 2에 가 까운 $1.33 \sim 2.27$ 로 나타나 오차항의 자기상관 문제가 없었다 (B. H. Yang, 2000). 분산팽창계수값도 $1.00 \sim 1.59$ 범위로 기준 치 10 보다 매우 낮게 나타나(B. H. Yang, 2000), 결과적으로 독 립변인 간 다중공선성의 위험은 없는 것으로 나타났다.

유아교사의 발달에 적합한 교육신념이 수학교과교육학지
식에 영향을 미치는 과정에서 보육과정실행이 매개역할을 하 는지 알아보기 위해 Baron과 Kenny (1986)의 매개효과 검증절 차에 따라 회귀분석을 실시하였고, Sobel test를 실시하여 통계 적 검증을 하였다.

본 연구의 유아교사의 발달에 적합한 교육신념이 유아교사 의 수학교과교육학지식에 미치는 영향에서 보육과정실행의 매개효과를 알아보기 위하여 중다회귀분석을 실시한 결과 1 단계에서 유아교사의 발달에 적합한 교육신념이 매개변인인 보육과정실행에 미치는 영향력은 통계적으로 유의하게 나타 났고 $(\beta=.41, p<.001), 2$ 단계에서 독립변인인 유아교사의 발 달에 적합한 교육신념이 종속변인인 유아교사의 수학교과교 육학지식에 미치는 영향력은 통계적으로 유의하였다 $\beta=.40$, $p<.001)$. 그리고 3 단계에서 매개변인인 보육과정실행이 유 아교사의 수학교과교육학지식에 미치는 영향력도 유의하였 으며 $(\beta=.60, p<.001)$, 유아교사의 발달에 적합한 교육신념이 유아교사의 수학교과교육학지식에 미치는 영향력이 2 단계 $(\beta$ $=.40, p<.001)$ 보다 3 단계 $(\beta=.15, p<.01)$ 에서 줄어들었다. 따 라서 보육과정실행이 유아교사의 발달에 적합한 교육신념이 수학교과교육학지식에의 영향에서 부분매개효과를 가지는 것으로 나타났다. 또한 유아교사의 수학교과교육학지식에 대 한 설명력을 살펴보면, 유아교사의 발달에 적합한 교육신념이 단독으로 $16 \%$ 였으나 $(F=60.65, p<.001)$ 보육과정실행이 투 입되었을 때는 설명력이 $46 \%$ 로 늘었다 $(F=135.95, p<.001)$. Sobel test를 실시하여 매개효과의 유의성을 검증한 결과, 본 매 개효과는 유의한 것으로 나타났다 $(z=6.87, p<.001)$. 이를 통 
Table 4

The Direct and Indirect Influence of Education Beliefs in DAP to MPCK through Curriculum Implementation

\begin{tabular}{lcccc}
\hline & & 1 Step & 2 Step & 3 Step \\
\cline { 2 - 4 } & Variables & $\begin{array}{c}\text { Curriculum } \\
\text { implementation }(\beta)\end{array}$ & $\begin{array}{c}\text { MPCK } \\
(\beta)\end{array}$ \\
\hline Independent & Education belief in DAP & $.41^{* * *}$ & $.40^{* *}$ & \\
& & & & $.15^{* *}$ \\
& & & & $.60^{* * *}$ \\
Mediator & Curriculum implementation & & 2.44 & 1.34 \\
A constant & & 2.19 & .16 & .46 \\
$R^{2}$ & .17 & .16 & .45 \\
Adj. $R^{2}$ & & .17 & .16 & .46 \\
$\triangle R^{2}$ & & .17 & $60.65^{* * *}$ & $136.95^{* * *}$ \\
$F$ & & &
\end{tabular}

Note. $N=327$.

${ }^{* *} p<.01 .{ }^{* * *} p<.001$.

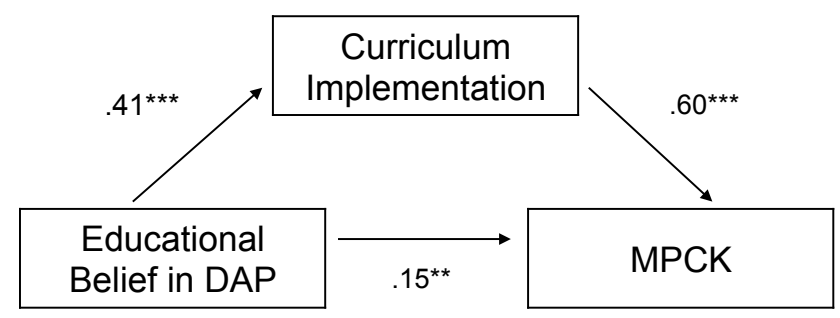

Figure 1. The mediating effects of curriculum implementation on the influence of education beliefs in DAP to MPCK.

Standardized coefficients are presented.

${ }^{* *} p<.01 .{ }^{* * *} p<.001$.

해 유아교사의 발달에 적합한 교육신념은 수학교과교육학지 식을 직접적으로 예측함과 동시에 보육과정실행을 통해 간접 적으로 예측함을 알 수 있다(Table 4, Figure 1).

유아수학에 대한 교사교육경험(양성과정이수, 현직과정연수)에 따라 유아교사의 발달에 적 합한 교육신념이 보육과정실행을 통해 수학교 과교육학지식에 미치는 직·간접적 영향

유아교사의 교사교육경험에 따라 유아교사의 발달에 적합한 교육신념이 수학교과교육학지식에 미치는 영향이 어떠한지 알아보기 위하여 유아교사의 유아수학에 대한 교사교육경험 을 양성과정 이수와 교사가 된 이후의 현직과정 연수로 나누 어 중다회귀분석을 실시하였다.

\section{양성과정이수에 따른 결과}

중다회귀분석 결과 유아교사 양성과정 중 유아수학에 대한 교 사교육을 이수한 경우 유아교사의 발달에 적합한 교육신념 이 유아교사의 보육과정실행에 유의한 영향을 미치는 것으로 나타났으며 $(\beta=.40, p<.001)$, 수학교과교육학지식에도 유의 한 영향을 미치는 것으로 나타났다 $(\beta=.44, p<.001)$. 또한 매 개변인인 보육과정실행이 유아교사의 수학교과교육학지식 에 미치는 영향력도 유의하였으며 $(\beta=.58, p<.001)$, 유아교 사의 발달에 적합한 교육신념이 유아교사의 수학교과교육학 지식에 미치는 영향력은 2 단계 $(\beta=.44, p<.001)$ 보다 3 단계 $(\beta$ $=.20, p<.001)$ 에서 줄어들었다. 따라서 보육과정실행이 유아 교사의 발달에 적합한 교육신념이 수학교과교육학지식에의 영향에서 부분 매개효과를 가지는 것으로 나타났다. 또한 유 아교사의 수학교과교육학지식에 대한 설명력을 살펴보면, 유 아교사의 발달에 적합한 교육신념이 단독으로 $19 \%$ 였으나 $(F$ $=53.32, p<.001)$ 보육과정실행이 투입되었을 때는 설명력이 $48 \%$ 로 늘었다 $(F=102.35, p<.001)$. Sobel test를 실시하여 매 개효과의 유의성을 검증한 결과, 본 매개효과는 유의한 것으 로 나타났다 $(z=5.64, p<.001)$. 이를 통해 유아교사가 교사양 성과정에서 수학교육을 이수한 경험이 있을 경우 유아교사의 발달에 적합한 교육신념은 수학교과교육학지식을 직접적으 로 예측함과 동시에 보육과정실행을 통해 간접적으로 예측함 을 알 수 있다. 
유아교사 양성과정 중 유아수학에 대한 교사교육을 미이수 한 경우에도 유아교사의 발달에 적합한 교육신념이 유아교사 의 보육과정실행에 유의한 영향을 미치는 것으로 나타났으며 $(\beta=.42, p<.001)$, 수학교과교육학지식에도 유의한 영향을 미 치는 것으로 나타났다 $(\beta=.29, p<.01)$. 또한 매개변인인 보육 과정실행이 유아교사의 수학교과교육학지식에 미치는 영향 력은 유의하였으나 $(\beta=.65, p<.001)$, 발달에 적합한 교육신념 은 통계적으로 유의하지 않은 것으로 나타났다. 따라서 보육 과정실행이 유아교사의 발달에 적합한 교육신념이 수학교과 교육학지식에의 영향에서 완전 매개효과를 가지는 것으로 나 타났다. 또한 유아교사의 수학교과교육학지식에 대한 설명력 을 살펴보면, 유아교사의 발달에 적합한 교육신념이 단독으로 $9 \%$ 였으나 $(F=8.93, p<.01)$ 보육과정실행이 투입되었을 때는 설명력이 $43 \%$ 로 늘었다 $(F=35.98, p<.001)$. Sobel test를 실시 하여 매개효과의 유의성을 검증한 결과, 본 매개효과는 유의
한 것으로 나타났다 $(z=3.87, p<.001)$. 이를 통해 유아교사가 교사양성과정에서 유아수학교육을 이수한 경험이 없을 경우 유아교사의 발달에 적합한 교육신념은 보육과정실행을 통해 수학교과교육학지식을 간접적으로만 예측한다는 것을 알 수 있다(Table 5, Figure 2).

\section{현직과정연수에 따른 결과}

중다회귀분석 결과 교사가 된 이후에 유아수학에 대한 교사교 육을 연수한 경험이 있는 경우 유아교사의 발달에 적합한 교 육신념이 유아교사의 보육과정실행에 유의한 영향을 미치는 것으로 나타났으며 $(\beta=.33, p<.001)$, 수학교과교육학지식에 도 유의한 영향을 미치는 것으로 나타났다 $(\beta=.37, p<.001)$. 또한 매개변인인 보육과정실행이 유아교사의 수학교과교육 학지식에 미치는 영향력도 유의하였으며 $(\beta=.56, p<.001)$, 유

Table 5

The Direct and Indirect Influence of Educational Beliefs in DAP to MPCK according to the Experience of Pre-service Teacher Education on the Early Childhood Mathematices

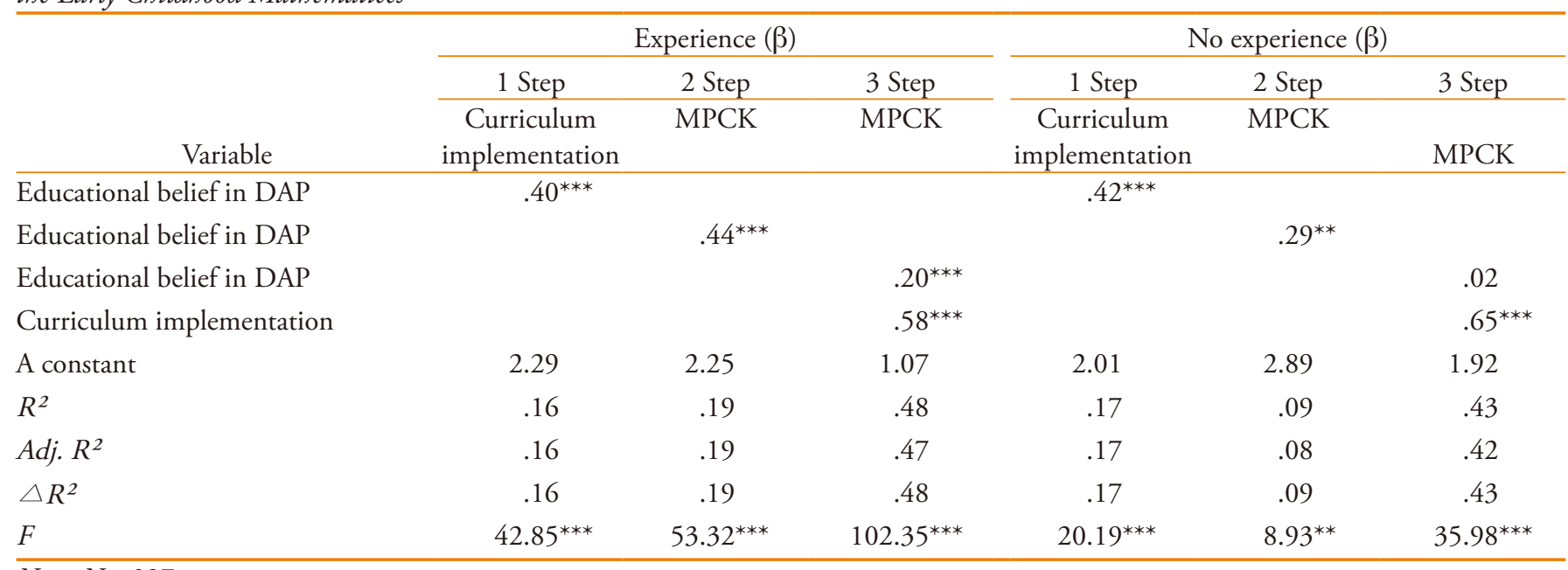

Note. $N=327$.

${ }^{* *} p<.01 .{ }^{* * *} p<.001$
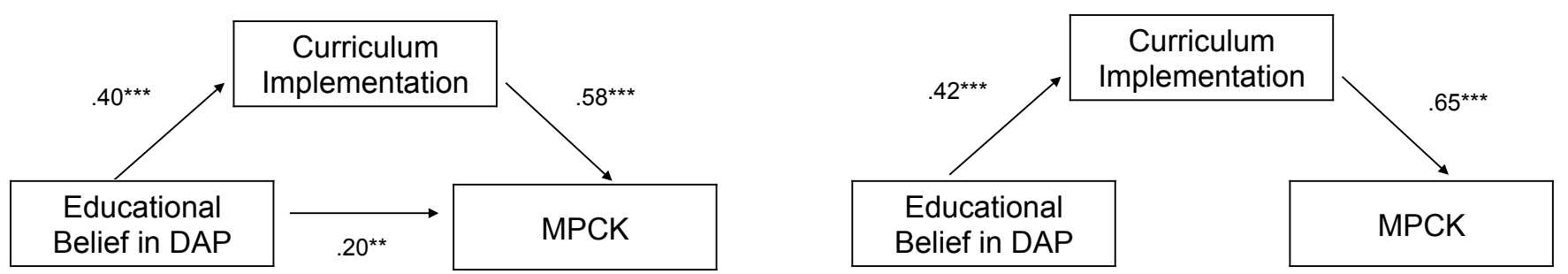

Figure 2. Mediating effects of curriculum implementation in a group with experience (right) and no experience (left) of pre-service teacher education on the early childhoold mathematics. Standardized coefficients are presented. ${ }^{* *} p<.01 .{ }^{* * *} p<.001$. 
Table 6

The Direct and Indirect Influence of Educational Beliefs in DAP to MPCK according to the Experience of In-service Teacher Education on the Early Childhood Mathematics

\begin{tabular}{|c|c|c|c|c|c|c|}
\hline \multirow[b]{3}{*}{ Variable } & \multicolumn{3}{|c|}{ Experience } & \multicolumn{3}{|c|}{ No experience } \\
\hline & 1 Step & 2 Step & 3 Step & 1 Step & 2 Step & 3 Step \\
\hline & $\begin{array}{c}\text { Curriculum } \\
\text { implementation }(\beta)\end{array}$ & $\begin{array}{c}\mathrm{MPCK} \\
(\beta)\end{array}$ & $\begin{array}{l}\mathrm{MPCK} \\
(\beta)\end{array}$ & $\begin{array}{c}\text { Curriculum } \\
\text { implementation }(\beta)\end{array}$ & $\begin{array}{c}\text { MPCK } \\
(\beta)\end{array}$ & $\begin{array}{c}\text { MPCK } \\
(\beta)\end{array}$ \\
\hline Educational belief in DAP & $.33^{* * *}$ & $.37^{* * *}$ & $.18^{* *}$ & $.47^{* * *}$ & $.42^{* * *}$ & .12 \\
\hline Curriculum implementation & & & $.56^{* * *}$ & & & $.64^{* * *}$ \\
\hline$R^{2}$ & .11 & .14 & .42 & .22 & .18 & .50 \\
\hline$R^{2}$ Variation & .10 & .13 & .41 & .21 & .17 & .49 \\
\hline$\triangle R^{2}$ & .11 & .14 & .42 & .22 & .18 & .50 \\
\hline$F$ & $18.82^{* * *}$ & $23.77^{* * *}$ & $53.70^{* * *}$ & $47.55^{* * *}$ & $36.25^{* * *}$ & $84.93^{* * *}$ \\
\hline
\end{tabular}

Note. $N=327$.

${ }^{* *} p<.01 .{ }^{* * *} p<.001$.
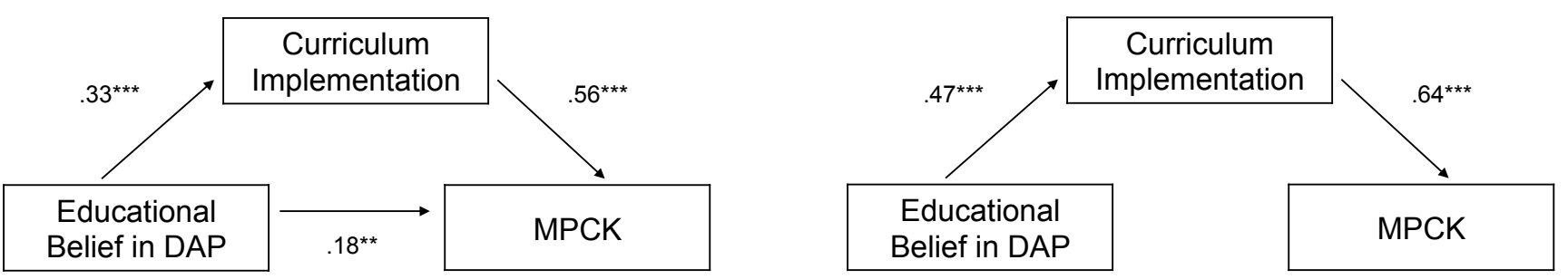

Figure 3. Mediating effects of curriculum implementation in a group with experience (right) and no experience (left) of in-service teacher education on the early childhoold mathematics. Standardized coefficients are presented.

${ }^{* *} p<.01 .{ }^{* * *} p<.001$.

아교사의 발달에 적합한 교육신념이 유아교사의 수학교과교 육학지식에 미치는 영향력은 2 단계 $(\beta=.37, p<.001)$ 보다 3 단 계 $(\beta=.18, p<.01)$ 에서 줄어들었다. 따라서 보육과정실행이 유아교사의 발달에 적합한 교육신념이 수학교과교육학지식 에의 영향에서 부분 매개효과를 가지는 것으로 나타났다. 또 한 유아교사의 수학교과교육학지식에 대한 설명력을 살펴보 면, 유아교사의 발달에 적합한 교육신념이 단독으로 $14 \%$ 였으 나 $(F=23.77, p<.001)$ 보육과정실행이 투입되었을 때는 설명 력이 $42 \%$ 로 늘었다 $(F=53.70, p<.001)$. Sobel test를 실시하여 매개효과의 유의성을 검증한 결과, 본 매개효과는 유의한 것 으로 나타났다 $(z=3.86, p<.001)$. 이를 통해 유아교사가 교사 가 된 이후 수학교육을 연수한 경험이 있을 경우 유아교사의 발달에 적합한 교육신념은 수학교과교육학지식을 직접적으 로 예측함과 동시에 보육과정실행을 통해 간접적으로 예측한 다는 것을 알 수 있다.
현직과정 중 유아수학에 대한 교사교육을 연수한 경험이 없는 경우에도 유아교사의 발달에 적합한 교육신념이 보육과 정실행에 유의한 영향을 미치는 것으로 나타났으며 $(\beta=.47, p$ $<.001)$, 유아교사의 수학교과교육학지식에도 유의한 영향을 미치는 것으로 나타났다 $(\beta=.42, p<.001)$. 또한 매개변인인 보육과정실행이 유아교사의 수학교과교육학지식에 미치는 영향력은 유의하였으나 $(\beta=.64, p<.001)$, 발달에 적합한 교육 신념은 통계적으로 유의하지 않은 것으로 나타났다. 따라서 보육과정실행이 유아교사의 발달에 적합한 교육신념이 수학 교과교육학지식에의 영향에서 완전 매개효과를 가지는 것으 로 나타났다. 또한 유아교사의 수학교과교육학지식에 대한 설 명력을 살펴보면, 유아교사의 발달에 적합한 교육신념이 단독 으로 $18 \%$ 였으나 $(F=36.25, p<.001)$ 보육과정실행이 투입되 었을 때는 설명력이 $50 \%$ 로 늘었다 $(F=84.93, p<.001)$. Sobel test를 실시하여 매개효과의 유의성을 검증한 결과, 본 매개효 
과는 유의한 것으로 나타났다 $(z=5.78, p<.001)$. 이를 통해 유 아교사가 교사가 된 이후 유아수학교육을 연수한 경험이 없을 경우 유아교사의 발달에 적합한 교육신념은 수학교과교육학 지식을 간접적으로만 예측할 뿐 직접적으로는 예측하지 않는 것을 알 수 있다(Table 6, Figure 3).

\section{논의 및 결론}

이 연구는 유아교사의 발달에 적합한 교육신념이 보육과정실 행을 통해 수학교과교육학지식에 직간접적으로 영향을 미치 는 경로를 검증하고, 이 경로가 유아교사의 양성 및 현직 과정 에서의 유아수학 관련 교육의 경험여부에 따라 다른 양상을 보이는지를 파악하고자 하였다. 이 연구에서 설정한 연구문제 에 대한 연구결과를 논의하면 다음과 같다.

첫째, 유아교사의 발달에 적합한 교육신념이 수학교과교육 학지식에 미치는 영향에서 보육과정실행의 매개효과를 분석 한 결과, 보육과정실행은 유아교사의 발달에 적합한 교육신념 이 수학교과교육학지식을 예측하는 과정을 부분적으로 매개 한다. 즉, 유아교사가 발달에 적합한 교육신념을 가지고 있을 수록 수학교과교육학지식의 수준이 높을 뿐만 아니라 유아교 사가 발달에 적합한 교육신념을 가지고 있을수록 보육과정실 행에 긍정적인 영향을 미쳐 수학교과교육학지식의 수준이 높 아질 수도 있음을 의미한다. 이는 유아의 발달에 적합한 내용 과 방식으로서의 수학활동에 대한 지식인 수학교과교육학지 식(H. Hong, 2014)이 구성주의를 발달적 근거로 하고 있는 발 달에 적합한 교육신념(Hwang \& Kang, 2003)을 교육적 기반 으로 하고 있음을 확인한 것이다. 유아교사의 발달에 적합한 교육신념이 높을수록 수학교과교육학지식이 높게 나타난다 는 점은 S. Yang과 Kim (2017)의 연구에서 밝혀진 부분이며, 유 아교사의 발달에 적합한 교육신념은 교실에서의 수학교수실 제와 관련이 있었다는 Chung (1994)의 연구결과와 맥을 같이 한다. 더 나아가 이 연구에서 확인된 부분은 발달에 적합한 교 육신념이 수학교과교육학지식을 예측하는 데 있어 보육과정 실행이 중요한 매개역할을 한다는 점이다. 이 연구에서는 유 아교사가 보육과정실행을 통해 발달에 적합한 교육신념이 수 학교과교육학지식으로 연결되는 경로를 발견하였는데, 이는 발달에 적합한 교육신념이 보육과정실행을 예측하기 때문이 다. 이는 보육과정실행에 변화를 가져오고자 할 때에 교사의 교육신념에 따라 변화의 성공과 실패가 좌우되기도 한다는 Spillane (2000)의 연구결과와 같은 맥락이다. 그 결과 유아교
사는 보육과정실행 과정을 통해 교사의 경험에 따라 계속적으 로 재구성 과정을 거치면서 더욱 효율적이고 전문적인 교사의 지식이 되는 수학교과교육학지식(Lim, 2003)을 높일 수 있는 것이다. 실제로 보육과정실행 정도가 높은 교사일수록 수학교 과교육학지식이 높게 나타났고(S. Yang \& Kim, 2017) 교과교 육학지식에 가장 많은 영향을 주는 것은 교실 수업실행 경험 이었다(Grossman, 1990). 따라서 수학교과교육학지식을 형성 하기 위해서는 보육현장의 보육과정실행을 통한 실천적 과정 이 중요하며, 더불어 교사양성과정에서부터 발달에 적합한 교 육신념 형성을 위한 교육이 이루어지면 이론적으로 수학교과 교육학지식을 형성할 수 있는 추가적인 기회가 제공된다는 점 을 유추할 수 있다.

둘째, 유아교사의 교사교육경험에 따라 유아교사의 발달에 적합한 교육신념이 수학교과교육학지식에 미치는 영향을 살 펴본 결과, 유아교사가 양성 및 현직 과정에서 유아수학에 대 한 교사교육경험이 있는 경우 유아교사의 보육과정실행은 발 달에 적합한 교육신념이 수학교과교육학지식에 미치는 영향 력을 부분적으로 매개한다. 그러나 유아수학에 대한 교사교 육경험이 없는 경우 유아교사의 보육과정실행은 발달에 적합 한 교육신념이 수학교과교육학지식에 미치는 영향력을 완전 매개한다. 이와 같은 차이는 유아수학에 대한 교사교육경험 이 없는 교사에게서 발달에 적합한 교육신념이 수학교과교육 학지식에 미치는 영향이 보육과정실행을 통해서만 존재할 수 있다는 점에 있다. 앞서 논의했듯이, 유아교사의 발달에 적합 한 교육신념은 수학교과교육학지식의 기반을 이룬다. 그러나 양성 및 현직 과정에서 유아수학에 대한 교사교육경험이 없는 유아교사의 경우 발달에 적합하게 보육과정을 실행하는 과정 을 통해 유아수학활동 영역에서도 어떻게 유아의 발달에 적합 한 내용과 방법으로 수학지도를 하는지에 대한 지식을 형성해 나갈 수 있는 것이다. 이는 수학교과교육학지식은 교사의 경 험에 따라 계속적으로 재구성 과정을 거치는 교사의 경험적이 고 실천적인 지식이라는 점(Lim, 2003)을 다시 한 번 확인해주 는 결과이다. 그러나 교과교육학지식이 이론 중심의 강의만으 로는 획득되기 어려워 교사의 반성적 수업 실천을 통해 형성 된다는 점(Choe \& Hwang, 2009)은 이론적 경험을 하지 않은 유아교사들도 보육과정실행이라는 실천적 과정을 바탕으로 수학교과교육학지식을 형성할 수 있음을 보여준다. 정부에서 는 국가수준의 보육과정인 3-5세 누리과정이 보육현장에서의 정착을 위해 누리과정 해설서, 교사용 지침서 및 지도서, 누리 과정 보육프로그램들과 같은 여러 교육자료들을 제공하였고 이와 관련된 연수를 실시함으로써 교사들이 누리과정을 익숙 
하게 실행할 수 있도록 지원하였다(Shin, 2013). 이러한 과정 을 통해 유아교사의 보육과정실행력이 높아지고, 그 결과 유 아수학에 대한 교사교육경험이 없는 교사도 보육과정실행 중 유아들과 발달에 적합한 수학활동을 반복적으로 실행하면서 수학교과교육학지식을 높일 수 있을 것이다.

이상을 통하여 본 연구의 최종적인 결론을 제시한다면, 유 아교사의 발달에 적합한 교육신념이 수학교과교육학지식을 높여주는 것은 보육과정실행의 매개를 통해서 부분적으로 이 루어지며, 유아교사가 양성 및 현직에서 유아수학에 대한 교 사교육경험이 없는 경우에는 보육과정실행을 통해서만 발달 에 적합한 교육신념과 수학교과교육학지식의 관계가 구축될 수 있다. 따라서 유아교사가 발달에 적합한 교육신념을 형성 할 수 있도록 영유아의 발달과 학습에 관련된 교육이 교사양 성과정과 현직교사의 보수 및 승급 교육과정의 내용으로 더욱 강화되어질 필요가 있다. 또한, 현장의 교사들이 어려움을 느 끼는 보육과정실행에 대한 평가 관련 교육이 강화되어, 유아 교사가 보육과정실행에서 평가한 결과를 다시 보육과정에 환 류하여 적용하는 과정을 통해 수학교과교육학지식이 지속적 으로 재구성되어질 수 있도록 지원하여야 할 것이다. 동시에 예비교사나 현직교사에게 유아수학교육이 실시되어 유아교 사의 발달에 적합한 교육신념이 수학교과에 어떻게 적용되는 지에 대한 이해와 교과내용 지식 형성을 도울 수 있는 프로그 램을 운영하는 것이 유아교사의 유아수학교육의 질 향상에 도 움이 될 것으로 사료된다.

본 연구는 통계방법으로 각 변인 간의 구조적인 인과관계 를 좀 더 규명해 줄 수 있는 방법을 실시하지 못했다는 점에서 제한점이 있다. 그러나 본 연구는 유아교사의 수학교과교육학 지식 향상을 위해 보육과정실행 수준을 높이고 교사교육경험 과정에서 발달에 적합한 교육신념을 형성하는 것의 중요성을 조명하였다는 점에서 의미가 있다. 이 연구결과는 수학교과교 육학지식의 향상을 위한 교사교육프로그램 개발에 기초자료 로 기여할 것이다.

\section{Notes}

This article was presented as at the 2017 Annual Fall Conference of the Korean Association of Child Studies.

\section{Conflict of Interest}

No potential conflict of interest relevant to this article was reported.

\section{References}

\section{In English}

Aubrey, C. (1994). The role of subject knowledge in the early years of schooling. London: Falmer Press.

Baron, R. M., \& Kenny, D. A. (1986). The moderator-mediator variable distinction in social psychological research: Conceptual strategic, and statistical considerations. Journal of Personality and Social Psychology, 51(6), 1173-1182. doi:10.1037//00223514.51.6.1173.

Bredekamp, S., \& Rosegrant, T. (1992). Reaching potentials: Appropriated curriculum and assessment for young children, 1, Washington, DC: NAEYC.

Chung, K. E. (1994). Young children's acquisition of mathematical knowledge and mathematics education in kindergarten (Doctoral dissertation). Retrieved from http://www.lib.driastate. edu/rtd/10688

Cross, C. T., Woods, T. A., \& Schweingruber, H. (2009). Mathematics learning in early childhood: Paths toward excellence and equity. Washington, DC: The National Acacemic Press.

Geary, D. C. (1994). Children's mathematical development. Washington, DC: American Psychological Association. doi:10.1037/10163-000

Gess-Newsome, J., \& Lederman, N. G. (Eds.) (1999). Examining pedagogical content knowledge: The construct and its implications for science education. Boston, MA: Kluwer Academic Publisher.

Ginsburg, H. P. (2006). Mathematical play and playful mathematics: A guide for early education. In D. G. Singer, R. M. Golinkoff, \& K. Hirsh-Pasek (Eds.), Play = Learning: How play motivates and enhances children's cognitive and social-emotional growth. New York: Oxford University Press. doi:10.1093/acprof: oso/9780195304381.003.008

Ginsburg, H. P., \& Ertle, B. (2008). Knowing the mathematics in early childhood mathematics. In O. N. Saracho \& B. Spodek (Eds.). Contemporary perspectives on mathematics in early childhood education. Charlotte, NC: Information Age Publishing, Inc.

Golbeck, S. L. (2001). Instructional models for early childhood: In search of a child-regulated/teacher-guided pedagogy. In S. L. Golbeck (Ed.), Psychological perspectives on early childhood education. Mahwah, NJ: Lawrence Erlbaum Associates Publishers. 
Grossman, P. L. (1990). The making of a teacher: Teacher knowledge and teacher education. New York: Teachers College Press.

Hart, C., Burts, D., Charlesworth, R., Fleege, P., Ickes, M., \& Durland, M. (1990). The teachers questionnaire: Preschool version. School of Human Ecology. Baton Rouge, LA: Louisiana State University.

Hashweh, M. Z. (2005). Teacher pedagogical constructions: A reconfiguration of pedagogical content knowledge. Teachers and Teaching, 11(3), 273-292. doi:10.1080/13450600500105502

Moore, S., Widema, M. D., \& Dilling, H. J. (1984). Curriculum implementation: A Survey of teachers' level-of-use "The program and the six-year old" and "Social environmental studies (Grade 5-6)". (Report No. ED291612). Scarborough, ON: Scarborough Board of Education.

Lee, S. M. (2003). Korean early childhood educators' beliefs and best practices; The impact of education, experience, and teaching context (Doctoral dissertation). Retrieved from http://www. riss.kr/link?id=T9588261

Shulman, Lee. S. (1986). Those who understand: Knowledge growth in teaching. Educational Researcher, 15(2), 4-14. https://www.jstor.org/stable/24636916

Spillane, J. P. (2000). A fifth-grade teachers' reconstruction of mathematics and literacy teaching: Exploring interaction among identity, learning, and subject matter. The Elementary School Journal, 100(4), 307-330. doi:10.1086/499644

Thompson, A. (1992). Teachers' beliefs and conceptions: A synthesis of the research. In D. A. Grouws (Ed.). Handbook of research on mathematics teaching and learning (pp. 127146). New York: Macmillan Publishing Co, Inc.

Van Driel, J. H., Beijaard, D., \& Verloop, N. (2001). Professional development and reform in science education: The role of teacher's practical knowledge. Journal of Research in Science Teaching, 38(2), 137-158. doi:10.1002/10982736(200102)38:2<137::AID-TEA1001>3.0.CO;2-U

\section{In Korean}

Cho, B. W. (2010). A study of kindergarten preservice teacher's mathematics subject knowledge and their mathematics teaching efficacy beliefs. Korean Journal of Early Childhood Education, 30(5), 241-262.

Cho, I. J. (2008). An analysis and development on the alternative school teachers' educational belief scale. The Journal of Korean Teacher Education, 25(3), 1-24.

Choe, S. H., \& Hwang, H. J. (2009). The research on pedagogical content knowledge(PCK) focused on instructional consulting for secondary beginning teachers. Journal of the Korean School Mathematics Society, 12(1), 27-45.

Choi-Koh, S.-S., Kim, E.-H., Moon, J.-Y., Bae, J.-E., \& Jeong, D.J. (2011). A study on the relationship between pedagogical content knowledge and pre-service mathematics teacher's beliefs. Journal of Research in Curriculum \& Instruction, 15(4), 829-856.

Han, J. (2011). Pre-service and in-service early childhood teachers' beliefs about the nature of mathematics. Early Childhood Education Research \& Review, 14(6), 337-358.

Hong, H. J. (2012). Development and validation of assessment tools for kindergarten teachers' pedagogical content knowledge of mathematics teaching (Doctoral dissertation). Retrieved from http://www.riss.kr/link?id=T12892461

Hong, H. J. (2013). A study on the variables influencing kindergarten teachers' pedagogical content knowledge in mathematics. Early Childhood Education Research \& Review, 17(2), 429447.

Hong, H. (2010). The Future directions and challenges in early childhood mathematics education. Early Childhood Education Research \& Review, 14(4), 29-51.

Hong, H. (2014). Perceptions of early childhood teachers about mathematical knowledge for teaching. Journal of Early Childhood Education, 34(1), 157-175.

Hwang, Y.-S., \& Kang, H.-S. (2003). A preliminary investigation on the reconceptualization of DAP in early childhood curriculum construction. The Journal of Curriculum Studies, 21(2), 193-219.

Kim, J.-E. (2014). Relationships among kindergarten teachers' pedagogical content knowledge in mathematics, attitude toward mathematics and mathematics teaching efficacy. Journal of Children's Literature \& Education, 15(3), 383401.

Kim, J.-E., \& Hong, S.-O. (2015). Development and application of teacher training program for early childhood mathematics education based on pedagogical content knowledge (PCK). Journal of Early Childhood Education, 35(4), 5-30.

Kim, N.-H., Seo, B.-S., \& Shon, Y.-J. (2017). Pre-service early childhood teachers' pedagogical content knowledge on mathematics education through network analysis. Early Childhood Education Research \& Review, 21(2), 53-77.

Kim, N. Y., \& Park, E. H. (2017). The relationship between early childhood teacher's pedagogical content knowledge in mathematics and attitude towards mathematics. The Journal of Korean Teacher Education, 34(2), 439-463.

Kim, S. R. (2017). The relationships among mathematics pedagogical content knowledge, mathematical attitude and mathematics teaching efficacy of pre-service early childhood teachers. The Journal of Humanities and Social Sciences 21, 8(2), 691-706. doi:10.22143/HSS21.8.2.37

Kim, S. W., \& Choi, Y. S. (2001). Ingwa mohyeongui ihaewa hwalyong[인과모형의 이해와 활용] Seoul: Hakjisa.

Kwon, C. G. (1998). The relationships between the kindergarten teachers' beliefs and the children's developmental levels 
(Doctoral dissertation). Retrieved from http://www.riss.kr/ link?id=T10938876

Kwon, Y. H., Choi, M. W., \& Rha, J. H. (2011). Child care curricula according to teacher's teaching method types. Korean Journal of Human Ecology, 20(2), 353-364.

Kye, Y. H. (2011). A qualitative research of mathematical understanding for kindergarten's teachers about early childhood mathematics education. The Mathematical Education, 50(1), 119-128.

Lee, H.-J., Ham, E.-S., \& Kim, K. (2003). A study of educational belief and teacher's sense of self-efficacy of day-care teachers. Korea Journal of Child Care and Education, 32, 169-189.

Lee, J. M. (2007). A study on daycare center teacher's belief about developmentally appropriate practice and teacher-infant interactions (Master's thesis). Retrieved from http://www. riss.kr/link?id=T11293877

Lee, J. S., \& Oh, Y. J. (2006). The relationships among daycare center teacher's beliefs of DAP, teaching practices of DAP and teaching efficacy. Journal of Early Childhood Education \& Educare Welfare, 10(3), 103-124.

Lee, J.-W. (2000). Teacher knowledge in early childhood teacher education. The Journal of Korean Teacher Education, 17(1), 355-378.

Lee, K. S. (2008). Curriculum for young children. Paju: Kyomunsa.

Lee, S. A., \& Lee, S. M. (2007). Study on correlation between early childhood teachers' belief of DAP education and real status of DAP education. Journal of Future Early Childhood Education. 13(2), 249-275.

Lim, C.-H. (2003). Science teaching practice and science teaching efficacy beliefs by development of elementary school teachers' pedagogical content knowledge. Journal of Korean Earth Science Society, 24(4), 258-272.

Ministry of Health and Welfare (2014). 3-5se younryeongbyeol nurigwajeong[3-5세 연령별 누리과정]. Seoul: MHW.

Nam, M. K., \& Hwang, H. I. (2001). Developmentally appropriate practice: The beliefs and practices of kindergarten principals and teachers. Korea Journal of Child Studies, 22(3), 167181 .
Park, S. R. (2009). The possibilities and limitations on teacher's variables in curriculum implementation research. Journal of Learner-Centered Curriculum and Instruction, 9(1), 223240.

$\mathrm{Pu}, \mathrm{S}$. S. (1998). A study of teacher's stage of concern and level of use on the national kindergarten curriculum (Master's thesis). Retrieved from http://www.riss.kr/link?id=T7109643

Seo, J. M. (2017). Relationships among the teachers' belief, mathematics teaching efficacy, pedagogical content knowledge of mathematics and teaching intention for mathematics of early childhood teachers (Master's thesis). Retrieved from http://www.riss.kr/link?id=T14396686

Shin, K. H. (2013). A study on the investigation for teacher's degree of concern and application level at kindergarten and child care center about nuri curriculum for 5-years old (Master's thesis). Retrieved from http://www.riss.kr/link?id=T13151715

Sohn, S. Y. (2013). Teacher's perception, level of use, and the evaluation of the Nuri curriculum for age 5 (Doctoral dissertation). Retrieved from http://www.riss.kr/link?id=T13079531

Yang, B. H. (2000). Sahoejosa bunseoksa sahoetonggye[사회조사분 석과 사회통계]. Seoul: Seungandang.

Yang, S., \& Kim, J. (2017). Characteristics of early childhood teachers as predictors of pedagogical content knowledge in mathematics. The Korean Journal of the Human Development, 24(3), 91-109.

\section{ORCID}

Jihyun Kim

http://orcid.org/0000-0001-7263-3008

Sunyoung Yang

Received December 31, 2017

Revision received March 27, 2018

Accepted April 7, 2018 